\title{
Smears and cultures for diagnosis of pulmonary tuberculosis in an asymptomatic immigrant population
}

This article was published in the following Dove Press journal:

International Journal of General Medicine

13 September 2013

Number of times this article has been viewed

\section{Roberto Assael \\ Joaquin Cervantes \\ Gerardo Barrera \\ Clinica Medica Internacional, Ciudad Juarez, Mexico}

Correspondence: Roberto Assael Av Ramon Rivera Lara \#9020, Fracc. Las Lunas, CP 32543, Ciudad Juárez, Mexico

Tel +52656323 I740

Email jcervantes.cmi@gmail.com
Background: The World Health Organization estimated in 2010 that 8.8 million new tuberculosis (TB) cases. About one-third of the world's population is infected and $10 \%$ will develop active TB disease. While cultures remain the international gold standard for diagnosing TB disease, in many other low-income countries, sputum smears remain the only and most accessible tool with which to diagnose active TB disease. As a consequence, in patients with TB who have negative smears, their TB remains undetected.

Aim: The objective of the study reported here was to demonstrate the proportion of smearpositive/culture-positive cases compared with smear-negative/culture-positive TB cases in Mexican immigrants bound for the USA.

Methods: A retrospective study was undertaken of the medical records of 122 active TB cases diagnosed at a clinic in Ciudad Juarez, Mexico, from 2009 to 2012. All cases were confirmed by culture, regardless of the sputum smear results.

Results: Of the cases, $80 \%$ (97 active TB cases) had negative sputum smears, while only 25 cases $(20 \%)$ had at least one positive smear. All of the cultures were confirmed as positive for Mycobacterium tuberculosis complex.

Conclusion: The fact that $80 \%$ of the TB cases were smear negative and $20 \%$ smear positive shows that there is a clear gap between the actual state of active TB disease within patients under screening conditions, meaning that eight out of ten actual cases are being missed when sputum smear is the only diagnostic tool in asymptomatic patients with abnormal chest X-rays. Based on these results, it is highly recommended that countries that have not standardized culturing as the gold standard for the diagnosis of active TB do so, so that TB cases - which may endanger global public health - are not missed. It is also recommended that further studies be undertaken to determine the clinical background of the patients diagnosed by smear and culture to identify a direct relationship between clinical signs and symptoms and the smear result.

Keywords: TB, screening, Mexico, mycobacteria growth indicator tube, Löwenstein-Jensen agar

\section{Introduction}

The World Health Organization estimated in 20108.8 million new tuberculosis (TB) cases globally. More than 2 billion people (about one-third of the world's population) are estimated to be infected with Mycobacterium tuberculosis (latent tuberculosis infection). Of this infected population, 10\% will develop active TB disease throughout their lives. ${ }^{1,2}$

There are several risk factors that promote the development of active TB disease, such as immunologic response, substance abuse (tobacco, alcohol, and drugs), 
nutritional status (underweight, vitamin D deficiency), systemic diseases such as diabetes, high blood pressure, and renal impairment. ${ }^{2}$ Further, migration and endemics of the disease are important identifiable factors in TB infection. ${ }^{3}$ Increased travel from endemic TB countries into the USA, represents a challenge to TB control. Mexico represents one of the top countries with the majority of foreign-born active cases in the USA. , $^{3,6}$

The Centers for Disease Control and Prevention (CDC), along with the US Department of State, established that any foreign applicant for an immigrant visa for the USA must be screened outside the country for infectious diseases such as TB as part of the legal immigration process. Those authorized to perform the screening process are called "panel physicians." 5,8

Evaluation and diagnosis procedures for TB are based on clinical or radiological grounds. ${ }^{4}$ Once clinical or radiological suspicion is established, microbiological assessment is used to confirm the diagnosis of active TB disease. The diagnosis of TB is confirmed by isolation of the organism from secretions or tissue. ${ }^{7}$

While culturing remains the international gold standard for the diagnosis of TB disease, in many low-income countries sputum smears, which are known to be less sensitive and specific, remain the only and most accessible tool with which to diagnose active TB disease.

\section{Methods}

A retrospective study was performed on the medical records of 122 active TB cases diagnosed at a clinic in Ciudad Juarez, Chihuahua, Mexico, from January 2009 to December 2012. All of the active TB cases were Mexican immigrants bound for the USA who needed to be screened as part of the legal immigration process established by the US Department of State. Every TB case was confirmed by culture, regardless of sputum smear results. The medical files were reviewed extensively to determine whether each patient had a positive smear besides a positive culture for M. tuberculosis complex, which was identified by DNA probe. Both smear testing, using the Ziehl-Neelsen technique, and culturing on solid (Löwenstein-Jensen agar) and liquid (mycobacteria growth indicator tube) media were utilized with every sample collected, as per the CDC technical instructions for panel physicians.

After the data were gathered and grouped by smear results, each case was analyzed to determine parameters such as age, sex, city of origin, first smear result, and first culture result (which was defined for the purposes of this research as the first positive test obtained for at least one of three initial samples on consecutive days). A database containing all this information was created and analyzed using Epi Info ${ }^{\mathrm{TM}}$ (v 7.0, CDC, Atlanta, GA, USA).

The study had no ethical conflicts and access to information was granted by the clinic and the patients themselves, who provided informed consent.

\section{Results}

A total of 122 medical files were analyzed, of which $58 \%$ were male and $42 \%$ were female, giving a 1:1 ratio. The mean age of those with active TB was 61.4 years old. The youngest patient was 19 years old and the oldest 93 years old. Active TB disease was most prevalent in the Mexican state of Jalisco, followed by in Chihuahua, Guerrero, and Baja, California, all of which have a high immigration index rate.

On the smear results, $80 \%$ (97) of the active TB cases had negative sputum smears, while only $20 \%$ (25 cases) had positive smears. All of the cultures reported were positive for M. tuberculosis complex.

\section{Discussion and conclusion}

The fact that $80 \%$ of the TB cases were smear negative and $20 \%$ smear positive shows that there is a clear gap between the actual state of active TB disease within patients under screening conditions, meaning that eight out of ten actual cases are being missed when sputum smear is the only diagnostic tool in asymptomatic patients with abnormal chest X-rays.

In screening Mexican immigrants bound for the USA, culturing as a diagnostic tool was extremely useful to identify active TB cases before they crossed the border into the USA. Currently in Mexico, culturing is not standardized via the national health regulations as a routine process for the diagnosis of TB and smears are indicated for the asymptomatic population.

Based on the results of this study, it is highly recommended that Mexico and other low-income countries that have not standardized culturing as the gold standard for the diagnosis of active TB do so - by solid media (Löwenstein-Jensen agar) and mycobacteria growth indicator tube - so that TB cases which may endanger global public health - are not missed.

It is also recommended that further studies be undertaken to determine the clinical background of the patients diagnosed by smear and culture to identify a direct relationship between clinical signs and symptoms and the smear result. 


\section{Author contributions}

All authors contributed equally to this work. All authors contributed to data analysis, drafting and revising of the paper.

\section{Disclosure}

The authors declare no conflicts of interest in this work.

\section{References}

1. Lönnroth K, Raviglione M. Global epidemiology of tuberculosis: prospects for control. Semin Respir Crit Care Med. 2008;29(5): 481-491.

2. World Health Organization (WHO). Global Tuberculosis Control: Surveillance, Planning, Financing. WHO Report 2008 WHO/HTM/ TB/2008.393. Geneva: WHO; 2008. Available at: http://www.who.int/tb/ publications/global_report/2008/en/index.html. Accessed April 30, 2013.

3. Corbett EL, Watt CJ, Walker N, et al. The growing burden of tuberculosis: global trends and interactions with the HIV epidemic. Arch Intern Med. 2003;163(9):1009-1021.
4. Pablos-Méndez A, Blustein J, Knirsch CA. The role of diabetes mellitus in the higher prevalence of tuberculosis among Hispanics. Am J Public Health. 1997;87(4):574-579.

5. Centers for Disease Control and Prevention (CDC). Reported HIV status of tuberculosis patients - United States, 1993-2005. MMWR Morb Mortal Wkly Rep. 2007;56(42):1103-1106.

6. Bennett DE, Courval JM, Onorato I, et al. Prevalence of tuberculosis infection in the United States population: the national health and nutrition examination survey, 1999-2000. Am J Respir Crit Care Med. 2008;177(3):348-355.

7. Taylor Z, Marks SM, Ríos Burrows NM, Weis SE, Stricof RL, Miller B. Causes and costs of hospitalization of tuberculosis patients in the United States. Int J Tuberc Lung Dis. 2000;4(10):931-939.

8. CDC. Technical instructions for panel physicians [web page on the Internet]. Atlanta, GA: CDC; 2009. Available at: http://www.cdc.gov/ immigrantrefugeehealth/exams/ti/panel/technical-instructions-panelphysicians.html. Accessed August 19, 2013.
International Journal of General Medicine

\section{Publish your work in this journal}

The International Journal of General Medicine is an international, peer-reviewed open-access journal that focuses on general and internal medicine, pathogenesis, epidemiology, diagnosis, monitoring and treatment protocols. The journal is characterized by the rapid reporting of reviews, original research and clinical studies across all disease areas.

\section{Dovepress}

A key focus is the elucidation of disease processes and management protocols resulting in improved outcomes for the patient.The manuscript management system is completely online and includes a very quick and fair peer-review system. Visit http://www.dovepress.com/ testimonials.php to read real quotes from published authors.

Submit your manuscript here: http://www.dovepress.com/international-journal-of-general-medicine-journal 